\title{
ANALISIS NILAI TAMBAH OLAHAN GULA AREN DI KELOMPOK USAHA BERSAMA (KUB) GULA SEMUT AREN (GSA)
}

\author{
H. Miftah ${ }^{1 \mathrm{a}}$, A. Yoesdiarti ${ }^{1}$ dan MH. Maulana ${ }^{1}$ \\ ${ }^{1}$ Jurusan Agribisnis, Fakultas Pertanian, Universitas Djuanda Bogor \\ Jl. Tol Ciawi No. 1, Kotak Pos 35 Ciawi, Bogor 16720. \\ a Korespondensi: Himmatul Miftah, E-mail: himmatul.miftah@unida.ac.id
}

\begin{abstract}
This study aims to determine the added value and advantages of processing palm sugar on the KUB of "Sugar Palm Sugar" (GSA) in Wanasari Village, Cibeber District, Lebak Regency, Banten Province. The study was conducted in August-October 2017. Methods of data collection were carried out through observation and interviews. The research respondents were 24 craftsmen who were members of the KUB GSA. Data analysis was performed using a value-added formula using the Hayami method. The results showed that the value per kilogram of the product was the yield of $18.18 \%$, the output price of Rp. 10,500, - an added value of Rp. 1,030.75 / $\mathrm{kg}$ and a value added ratio of $53.99 \%$.

Keywords : Added Value, Advantages Of Processors, Methods of Hayami, Palm Sugar, KUB $G S A$
\end{abstract}

\begin{abstract}
ABSTRAK
Penelitian ini bertujuan untuk mengetahui nilai tambah dan keuntugan pengolahan gula aren di KUB "Gula Semuat Aren "(GSA) Desa Wanasari Kecamatan Cibeber Kabupaten Lebak Provinsi Banten. Penelitian dilakukan pada bulan Agustus-Oktober 2017. Metode pengumpulan data dilakukan melalui observasi dan wawancara. Responden penelitian adalah 24 orang pengrajin aren anggota KUB GSA. Analisis data dilakukan dengan menggunakan formula nilai tambah menggunakan metode Hayami. Hasil penelitian menunjukan bahwa nilai per kilogram produk yaitu rendemen sebesar 18,18\%, harga output Rp 10.500,- nilai tambah sebesar Rp. 1.030,75 / kg dan rasio nilai tambah 53,99\%.

Kata kunci : Nilai Tambah, Keuntungan Pengolah, Metode Hayami, Gula Aren, KUB GSA,
\end{abstract}




\section{PENDAHULUAN}

Provinsi Banten adalah salah satu provinsi yang memiliki potensi untuk dapat dikembangkan.Dari segi kualitas, gula aren yang dihasilkan Provinsi Banten salah satunya yaitu dalam bentuk gula semut aren. Produksi aren di Provinsi Banten (ton per tahun) Tahun 2015, pada tahun 2010 sampai dengan tahun 2014 yang memiliki produksi tertinggi di Provinsi Banten dari beberapa Kabupaten dan Kota yaitu Kabupaten Lebak. Pada tahun 2011 total produksi aren di Kabupaten Lebak mengalami peningkatan sebanyak $26,1 \%$ dari tahun sebelumnya, namun pada tahun 2012 hingga tahun 2013 total produksi aren mengalami penurunan produksi sebesar 20,1 \%dan pada tahun 2014 total produksi aren di Kabupaten Lebak mengalami peningkatan kembali sebesar 4,5\% Berdasarkan data diatas menunjukan bahwa total produksi aren di Kabupaten Lebak mengalami fluktuasi dari tahun 2010 hingga pada tahun 2014.

Kabupaten Lebak memiliki potensi yang cukup baik dibandingkan dengan Kabupaten dan Kota lainnya. Luas Areal Tanaman Aren di Kabupaten Lebak pada tahun 2013 mencapai 2.496,70 Ha, dengan produksi sebesar 1.384,00 Ton (setara Nira) dengan tingkat produktivitas sebesar 991,40 Kg/Ha. Beberapa kecamatan di Kabupaten Lebak yang mempunyai potensi pengembangan Aren salah satunya adalah Kecamatan Cibeber (Dinas Kehutanan dan Perkebunan Provinsi Banten, 2014). Kecamatan Cibeber terdapat salah satu kelompok pengrajin gula aren yaitu Kelompok Usaha Bersama (KUB) Gula Semut Aren (GSA), KUB GSA merupakan kelompok pengrajin aren terbesar di Kecamatan Cibeber yang menaungi dan menampung 11 desa pengrajin aren.

Potensi aren di KUB GSA belum dimanfaatkan secara maksimal karena belum semua pohon aren diberdayakan oleh para pengrajin aren di Kecamatan Cibeber. Hal ini dikarenakan harga gula di KUB GSA tergolong lebih rendah dibandingkan dengan di pasar.
Penelitian ini bertujuan untuk mengetahui :

1. Aktivitas yang dilakukan di unit pengolah gula Aren

2. Besar keuntungan yang diperoleh oleh para pelaku pengolah gula aren

3. Mengetahui nilai tambah dan margin yang diperoleh para pelaku gula semut aren di KUB GSA Desa Wanasari

\section{METODE PENELITIAN}

Penelitian ini dilaksanakan di Kelompok Usaha Bersama (KUB) Gula Semut Aren (GSA) di Desa Wanasari Kecamatan Cibeber Kabupaten Lebak Provinsi Banten sebagai wilayah pengrajin gula aren semut. Pemilihan lokasi penelitian dilakukan secara sengaja (purposive). Penelitian ini dilakukan mulai dari bulan Agustus-Oktober 2017.

Penelitian ini menggunakan data primer dan data sekunder. Data primer didapatkan dari responden melalui wawancara langsung dan melalui pengisian kuesioner yang telah disiapkan. Sedangkan data sekunder merupakan data penunjang yang diperoleh melalui literatur-literatur seperti jurnal ilmiah, Badan Pusat Statistik, Dinas Perindustrian dan Perdagangan Kabupaten Banten, Dinas Perkebunan Provinsi Banten,kajian penelitian terdahulu, buku, serta dengan melakukan studi pustaka.

Pengumpulan data dilakukan dengan cara pengamatan secara langsung dan wawancara di wilayah penelitian, sedangkan responden untuk pengrajin arenpengambilan responden dilakukan secara purposive sampling.

Kriteria pada responden pengrajin aren diantaranya :

1) Pengalaman sebagai pengrajin aren lebih dari 20 tahun

2) Sekala usaha penyadapan lebih dari 2 pohon aren

3) pengrajin aren yang fokus pada produksi gula semut aren. 
Adapun jumlah responden dengan metode purposiveyang diantaranya 24 orang pengrajin aren.

Penelitian dilakukan dengan pendekatan metode kualitatif dan kuantitatifuntuk mengolah data primer dan sekunder. Untuk menganalisis rantai nilai digunakan data kualitatif dan kuantitatif. Data kualitatif dilakukan secara deskriptif sesuai dengan identifikasi pelaku pengolah gula aren, dan analisis kuantitatif menggunakan analisis nilai tambah menggunakan metode Hayami (1987). Konsep pendukung dalam analisis nilai tambah menurut hayami untuk subsistem pengolahan adalah sebagai berikut :

a. Faktor konversi, merupakan jumlah output yang dihasilkan satusatuan input.

Tabel 1 Perhitungan Nilai Tambah

\begin{tabular}{|c|c|c|}
\hline No. & Variabel & Nilai \\
\hline \multicolumn{3}{|c|}{ Output, Input dan Harga } \\
\hline 1. & Output $(\mathrm{Kg})$ & A \\
\hline 2. & Bahan Baku (Kg) & $\mathrm{B}$ \\
\hline 3. & Tenaga kerja (HOK) & $\mathrm{C}$ \\
\hline 4. & Faktor Konversi & $\mathrm{D}=\mathrm{A} / \mathrm{B}$ \\
\hline 5. & Koefisien tenaga kerja $(\mathrm{HOK} / \mathrm{Kg})$ & $\mathrm{E}=\mathrm{C} / \mathrm{B}$ \\
\hline 6. & Harga output $(\mathrm{Rp} / \mathrm{Kg})$ & $\mathrm{F}$ \\
\hline \multicolumn{3}{|c|}{ Penerimaan dan Keuntungan } \\
\hline 7. & Upah tenaga kerja $(\mathrm{Rp} / \mathrm{HOK})$ & $\mathrm{G}$ \\
\hline 8. & Harga bahan baku $(\mathrm{Rp} / \mathrm{Kg})$ & $\mathrm{H}$ \\
\hline 9. & Sumbangan Input lain $(\mathrm{Rp} / \mathrm{Kg})$ & $\mathrm{I}$ \\
\hline 10. & Nilai Output (Rp) & $\mathrm{J}=\mathrm{D} \times \mathrm{F}$ \\
\hline \multirow[t]{2}{*}{11.} & a. Nilai Tambah (Rp/Kg) & $\mathrm{K}=\mathrm{J}-\mathrm{H}-\mathrm{I}$ \\
\hline & b. Rasio Nilai Tambah (\%) & $\mathrm{L}=(\mathrm{K} / \mathrm{J}) \times 100 \%$ \\
\hline \multirow[t]{2}{*}{12.} & a. Pendapatan tenaga kerja $(\mathrm{Rp} / \mathrm{Kg})$ & $M=E \times G$ \\
\hline & b. Bagian tenaga kerja $(\%)$ & $N=(M / K) \times 100 \%$ \\
\hline \multirow[t]{2}{*}{13.} & a. Keuntungan $(\mathrm{Rp} / \mathrm{Kg})$ & $\mathrm{O}=\mathrm{K}-\mathrm{M}$ \\
\hline & b. Tingkat keuntungan (\%) & $\mathrm{P}=(\mathrm{O} / \mathrm{K}) \times 100 \%$ \\
\hline \multirow[t]{3}{*}{14.} & Marjin $(\mathrm{Rp} / \mathrm{Kg})$ & $\mathrm{Q}=\mathrm{J}-\mathrm{H}$ \\
\hline & a. Pendapatan tenaga kerja langsung $(\%)$ & $\mathrm{R}=(\mathrm{M} / \mathrm{Q}) \times 100 \%$ \\
\hline & b. Sumbangan input lain (\%) & $S=(I / Q) \times 100 \%$ \\
\hline
\end{tabular}

Sumber : Hayami et.al, 1987

Pada perhitungan nilai tambah dapat diketahui kategori suatu agrondustri berdasarkan rasio nilai tambahnya yaitu termasuk dalam kategori agroindustri bernilai tambah rendah, sedang atau tinggi. Kategori nilai tambah ditentukan dengan b. Koefisien tenaga kerja langsung, menunjukkan jumlah tenaga kerja langsung yang diperlukan untuk mengolah satu satuan input.

c. Nilai output, menunjukkan nilai output yang dihasilkan dari satu satuan input (Sudiyono dalam Marimin dan Nurul, 2011).

Kegiatan pengolahan nira menjadi gula semut aren, pengolahan lanjutan gula semut aren hingga peningkatan kualitas gula semut aren dapat dianalisis dengan menggunakan metode Hayami.Adapun Prosedur perhitungan nilai tambah mengikuti metode Hayami dapat dilihat pada Tabel 1. 


\section{Analisis Nilai Tambah pada Pengrajin Aren Gula Semut Aren}

Analisis niai tambah ini akan memberikan informasi mengenai faktorfaktor dari proses produksi yang menghasilkan atau meningkatkan nilai tambah atau sebaliknya.Perhitungan nilai tambah pada pengrajin aren dapat dilihat pada Tabel 16.

Dari hasil perhitungan nilai tambah pada Tabel 16, diketahui bahwa hasil produksi/output untuk satu kali proses produksi gula semut aren adalah sebesar $5,6 \mathrm{~kg}$ dengan penggunaan bahan baku/input rata-rata sebesar 30,9liter dan dalam produksi sebanyak 1 bulan (25 hari) rata-rata produksi yang dihasilkan yaitu sebesar 140,91 kg gula semut aren dengan penggunaan bahan baku/input sebesar $775,00 \mathrm{~kg}$ nira. Analisis Nilai Tambah merupakan pertambahan nilai pada suatu produk seteah dilakukan proses pengolahan lebih lanjut.

a. Output, Input dan Harga Bahan Baku Gula Semut Aren

Rata-rata penggunaan bahan baku berupa nira dalam proses pembuatan gula semut aren pada pengrajin aren di KUB GSA adalah 775.00 Liter per proses produks. Hasil produksi dari pengolahan rata-rata bahan baku per proses produksi adalah 140,91 kilogram produk berupa gula semut aren.

Tenaga kerja adalah jumlah orang yang dibutuhkan dalam proses produksi. Rata-rata pengrajin aren dalam proses pengolahan melakukan sendiri untuk dengan banyaknya produksi satu kali proses produksi dalam satu hari. Satu HKO adalah delapan jam atau enam jam kerja wanita. Besarnya nilai koefisien tenaga menunjukkan besarnya sumbangan tenaga kerja yang dibutuhkan untuk mengolah satu liter nira menjadi gula semut aren.

Nilai faktor konversi yaitu perbandingan antara output dengan input. Nilai faktor konversi untuk produk gula semut aren adalah jumlah output dibagi dengan input yang digunakan. Rata-rata nilai faktor konversi adalah sebesar 0,1818.
Nilai faktor konversi menunjukkan bahwa setiap 775,59 Liter nira mampu menghasilkan 140,91 kilogram gula semut aren.

Rata-rata nilai koefisien tenaga kerja sebesar 0,0240 menunjukkan bahwa untuk mengolah 140,91 kilogram gula semut aren diperlukan tenaga kerja langsung sebanyak 18,57HKO. Dari nilai koefisien tenaga kerja dapat dilihat apakah pengusaha sudah efisien berproduksi atau belum. Semakin kecil nilai koefisien tenaga kerja maka semakin efisien pengusaha berproduksi. Rata-rata harga jual dari pengrajin aren di KUB GSA gula semut aren di pengumpul desa adalah Rp 10.500 per kilogram.

b. Pendapatan dan Keuntungan

Besarnya pendapatan yang diterima oleh pengrajin aren diperoleh dari hasil kali antara koefisien tenaga kerja dengan rata-rata upah tenaga kerja. Besarnya ratarata upah tenaga kerja per proses produksi gula semut aren di KUB GSA adalah Rp 30.000 per HKO. Jadi besarnya pendapatan yang diterima oleh tenaga kerja langsung dari pengolahan satu kilogram nira menjadi gula semut aren adalah sebesar Rp 718,83 per liter, dengan bagian tenaga kerja sebesar $69,74 \%$ persen dari nilai tambah dan keuntungan yang diperoleh pengrajin aren dari proses pembuatan gula semut aren adalah $\mathrm{Rp} 311,93$ per $\mathrm{kg}$ atau 30,26\% dari nilai tambah produk.

Perhitungan nilai tambah bertujuan untuk mengetahui besarnya nilai tambah dalam satu liter nira setelah diolah menjadi gula semut aren. Besarnya nilai tambah tergantung pada biaya yang dikeluarkan meliputi biaya perolehan bahan baku dan sumbangan input lain. Sumbangan input lain terdiri dari seluruh biaya variabel kecuali biaya bahan baku dan upah tenaga kerja.

Hasil perhitungan nilai tambah yang diperoleh dari pengolahan nira menjadi gula semut aren pada pengrajin aren di KUB GSA adalah sebesar Rp 1.030,75per $\mathrm{kg}$ dengan rasio sebesar 53,99\%. Hal ini menunjukkan bahwa usaha pengolah nira menjadi gula semut aren pada pengrajin 
aren di KUB GSA tergolong dalam kategori bernilai tinggi yang dalam standar Metode Hayami memiliki nilai rasio berkisar antara $>40 \%$.

c. Balas Jasa Untuk Faktor Produksi

Balas jasa faktor produksi terdiri atas balas jasa untuk faktor produksi tenaga kerja, input lain, dan tingkat keuntungan. Marjin merupakan selisih harga atau nilai produk dengan nilai input bahan baku.
Marjin akan didistribusikan untuk imbalan tenaga kerja, sumbangan input lain dan keuntungan perusahaan.

Rata-rata marjin dari produksi gula semut aren adalah sebesar Rp 1.859,09 per kgnira, yang terdiri atas $38,67 \%$ pendapatan tenaga kerja, 44,56\% sumbangan input lain dan $16,78 \%$ keuntungan pengolahan untuk pengrajin aren.

Tabel 2. Analisis Nilai Tambah pada Pengrajin Aren

\begin{tabular}{|c|c|c|c|c|}
\hline No & Keterangan & Rumus & & Nilai \\
\hline \multicolumn{5}{|c|}{ Ouput, Input, dan Harga } \\
\hline 1 & Output berupa gula semut ( $\mathrm{Kg} /$ proses produksi) & A & & 140,91 \\
\hline 2 & Input Nira (kg/proses produksi) & B & & 775,00 \\
\hline 3 & Tenaga Kerja (HOK/proses produksi) & $\mathrm{C}$ & & 18,57 \\
\hline 4 & Faktor konversi & $\mathrm{D}=\mathrm{A} / \mathrm{B}$ & & 0,1818 \\
\hline 5 & Koefisien tenaga kerja & $E=C / B$ & & 0,0240 \\
\hline 6 & Harga Ouput $(\mathrm{Rp} / \mathrm{Kg})$ & $\mathrm{F}$ & $\mathrm{Rp}$ & $10.500,00$ \\
\hline \multicolumn{5}{|c|}{ Pendapatan dan Keuntungan } \\
\hline 7 & Upah tenaga kerja (Rp/HOK) & G & $\mathrm{Rp}$ & $30.000,00$ \\
\hline 8 & Harga bahan baku (Rp/Kg) & $\mathrm{H}$ & $\mathrm{Rp}$ & 50,00 \\
\hline 9 & Sumbangan input lain $(\mathrm{Rp} / \mathrm{Kg})$ & I & $\mathrm{Rp}$ & 828,34 \\
\hline 10 & Nilai Output (Rp) & $\mathrm{J}=\mathrm{D} \times \mathrm{F}$ & $\mathrm{Rp}$ & $1.909,09$ \\
\hline \multirow[t]{2}{*}{11} & a. Nilai Tambah $(\mathbf{R p} / \mathrm{kg})$ & $\mathrm{K}=\mathrm{J}-\mathrm{H}-\mathrm{I}$ & $\mathbf{R p}$ & $1.030,75$ \\
\hline & b. Rasio Nilai tambah (\%) & $\mathrm{L}=(\mathrm{K} / \mathrm{J}) \times 100 \%$ & & $53,99 \%$ \\
\hline \multirow[t]{2}{*}{12} & a. Pendapatan tenaga kerja $(\mathrm{Rp} / \mathrm{Kg})$ & $\mathrm{M}=\mathrm{E} \times \mathrm{G}$ & $\mathrm{Rp}$ & 718,83 \\
\hline & b. Bagian tenaga kerja (\%) & $\mathrm{N}=(\mathrm{M} / \mathrm{K}) \times 100 \%$ & & $69,74 \%$ \\
\hline \multirow[t]{2}{*}{13} & a. Keuntungan $(\mathrm{Rp} / \mathrm{Kg})$ & $\mathrm{O}=\mathrm{K}-\mathrm{M}$ & $\mathrm{Rp}$ & 311,93 \\
\hline & b. Tingkat keuntungan $(\%)$ & $\mathrm{P}=(\mathrm{O} / \mathrm{K}) \times 100 \%$ & & $30,26 \%$ \\
\hline \multicolumn{5}{|c|}{ Balas Jasa untuk Faktor produksi } \\
\hline \multirow[t]{4}{*}{14} & Marjin $(\mathrm{Rp} / \mathrm{Kg})$ & $\mathrm{Q}=\mathrm{J}-\mathrm{H}$ & $\mathrm{Rp}$ & $1.859,09$ \\
\hline & a. Pendapatan tenaga kerja (\%) & $\mathrm{R}=(\mathrm{M} / \mathrm{Q}) \times 100 \%$ & & $38,67 \%$ \\
\hline & b. Sumbangan input lain (\%) & $\mathrm{S}=(\mathrm{I} / \mathrm{Q}) \times 100 \%$ & & $44,56 \%$ \\
\hline & c. Keuntungan pengolah $(\%)$ & $\mathrm{T}=(\mathrm{O} / \mathrm{Q}) \times 100 \%$ & & $16,78 \%$ \\
\hline
\end{tabular}

\section{KESIMPULAN DAN IMPLIKASI KEBIJAKAN}

\section{Kesimpulan}

Berdasarkan hasil dan pembahasan yang dilakukan dalam penelitian maka dapat disimpulkan hal-hal sebagai berikut : Analisis nilai tambah menunjukan bahwa nilai tambah bernilai tinggi terdapat pada aktor UKM Pengolahan yaitu sebesar $36.293,72 / \mathrm{kg}$ atau $67,00 \%$ pada penjualan ke konsumen dengan kemasan $1 / 4 \mathrm{~kg}$ dengan marjin sebesar Rp. 57.650,00/kg, sedangkan nilai tambah bernilai rendah terdapat pada KUB GSA yaitu sebesar Rp. 641,69atau 4,48\% pada penjualan ke UKM Pengolahan dengan marjin sebesar Rp. $1.850,00 / \mathrm{kg}$. Nilai tambah yang diperoleh aktor UKM Pengolahan lebih besar dari aktor lainya karena adanya pengolahan lanjutan pada gula semut aren.

\section{Implikasi Kebijakan}

Saran pada penelitian ini adalah sebagai berikut : 
1. Usaha pengolahan dan pemasaran gula semut aren memiliki potensi untuk dikembangkan tetapi pengetahuan dan keterbatasan modal menjadi kendala dalam mengembangkan usaha ini. Oleh karena itu, perlunya perluasan informasi dan bantuan permodalan di KUB GSA Desa Wanasari dalam rangka meningkatkan nilai dan kualitas hasil gula semut aren.

2. Upaya yang dapat dilakukan untuk meningkatkan pendapatan pada pengrajin aren dapat dilakukan melalui aktivitas pada pengolahan yaitu dengan melakukan pengolahan lebih lama dari yang sebelumnya dilakukan untuk dapat memproduksi gula semut aren yang lebih kering dan melakukan penyaringan menggunakanayakan dengan ukuran mess 20 untuk dapat memperoleh gula semut aren yang lebih halus sesuai dengan kebutuhan konsumen, dengan melakukan aktivitas-aktivitas pada pengolahan gula semut aren maka pendapatan yang diterima pengrajin aren akan meningkat.

\section{DAFTAR PUSTAKA}

Apriyanto E, Setiadi D. 2016. Pengaruh Kondisi Tajuk dan Aplikasi Getar Terhadap Produksi Nira Aren di Rejang Lebong Bengkulu. Jurnal Pertanian TropikVol.3, No.2. Agustus2016. ISSN.

Asmarantaka, RW. 2012. Pemasaran Agribisnis (Agrimarketing). Bogor (ID): Institut Pertanian Bogor.

Badan Pusat Statistik (BPS). 2016. Provinsi Banten, Provinsi Jawa Barat, Provinsi Sumatra, Provinsi Sulawesi Tenggara, Provinsi Kalimantan Selatan, Sumatera Barat, Bengkulu, Sulawesi Utara, dan Maluku Utara dalam Angka 2016.www.bps.go.id (31 Agustus 2017)

DahlDc,HammondJW.1977. Market and Price Analysis The Agricultural Industry. Mc. Grawhill Book Company. New york.
Dinas Kehutanan dan Perkebunan Kabupaten Lebak. 2014. Rencana Strategis Dinas Kehutanan dan Perkebunan Kabupaten Lebak Tahun 2014 - 2019. Kabupaten Lebak. Banten.

Hayami, Y., Kawagoe, T., Marooka, Y., Siregar, M. 1987. Agricultural Marketing and Processing in Upland Java. A Perspective From A Sunda Village. CGPRT Center. Bogor.

Heryani H. 2016. Keutamaan Gula Aren dan Strategi Pengembangan Produk. Lambung Mangkurat University Press. Banjarmasin.

Hidayatulloh R, Djoko K, Budi S. 2015. Analisis Rantai Nilai (Value Chain) Usahatani Sayuran Organik (Studi Kasus Pada Komunitas Organik Brenjonk, Desa Penanggungan Kecamatan Trawas Kabupaten Mojokerto Jawa Timur. Program Pascasarjana. Fakultas Pertanian. Universitas Brawijaya. Jurnal :AGRISE Volume XV No. 1 Bulan Januari 2015.Malang.

Kaplinsky R dan Morris M. 2000. A Handbook For Value Chain Research. Prepared for the IDRC. Institute of Development Studies: Sussex.

KEMENTAN. 2015. Produksi Aren di Provinsi Banten (ton per tahun) tahun 2015. www.pertanian.go.id Agustus 2017)

Kohls, RLdan Uhl, JN. 2002.Marketing of Agricultural Products. New York (USA):Macmillan Publishing Company.

Porter ME. (1990). Competitive Strategy. Techniques for Analysing Industries and Competitors., New York: The Free Press.

Porter ME. (1994). Keunggulan Bersaing. Menciptakan dan Mempertahankan Kinerja Unggul. Binapura Aksana, Jakarta

Pietrobelli C, Rabelloti R. 2006. Upgrading of Global Value Chain Lessons From Latin American Clusters Elsevier LTD. Great Britain. 
Sampit. MM.I., Kindangen.P, dan Wulur. M, 2016. Analisis Rantai Nilai Gula Aren (Studi Kasus pada Petani Nira
Di Tomohon). Jurnal Emba. Vol.4 No.5 September, Hal. 303-408 